\title{
Teaching Reform of Algorithm Design and Analysis Course Based on "Project Oriented + Autonomous Learning + Practical Training"
}

\author{
Jufang $\mathrm{Li}^{1 *}$, Yuan Tang ${ }^{2}$, Yumei $\mathrm{Fu}^{3}, \mathrm{Ye} \mathrm{Yan}^{4}$ and Xiao Xiao ${ }^{5}$ \\ ${ }^{1}$ City College of Science and Technology, Chongqing University, Chongqing 402167, China \\ ${ }^{2}$ City College of Science and Technology, Chongqing University, Chongqing 402167, China \\ ${ }^{3}$ Chongqing University, Chongqing 400044, China \\ ${ }^{4}$ City College of Science and Technology, Chongqing University, Chongqing 402167, China \\ ${ }^{5}$ City College of Science and Technology, Chongqing University, Chongqing 402167, China \\ * Corresponding author
}

Keywords: Teaching Reform; Project orientation; Autonomous Learning; Practice Training

\begin{abstract}
Combined with the aim and idea of cultivating applied talents, this paper takes the course of "Algorithm design and Analysis" as the object of study. By trying to diversify the teaching model, aiming at the problems of teaching content, teaching mode and experimental training in the teaching of applied technology-oriented undergraduate colleges, this paper puts forward a teaching reform scheme based on "project-oriented + Autonomous Learning + practical training", which provides a train of thought for solving the existing teaching problems and improving the teaching quality of algorithm courses.
\end{abstract}

\section{Introduction}

Algorithm design and analysis is a compulsory basic course for undergraduates and graduate students majoring in computer science at home and abroad[1]. Along with the courses of data structure and programming language, it forms the core part of the curriculum system of computer science[2]. Algorithm design and analysis is a key index to measure software performance[3]. The main purpose of the course is to master the design, realization and comparison of algorithms through the systematic study and research of computer algorithms.

As an undergraduate college of applied technology, our school focuses on cultivating students' ability to design efficient algorithms for practical problems. In our school, the current Algorithm design and analysis courses are all theoretical teaching, the lack of practical teaching, in addition to the curriculum itself has a strong theoretical, wide range of knowledge and other factors, from the students' learning situation reflects that the teaching effect is not ideal.

\section{Analysis of Existing Problems in Algorithm Design and Analysis Course}

\subsection{Curriculum is very difficult and students' interest in learning is not high}

Arithmetic analysis plays a connecting role in the four-year university curriculum system. Its pilot courses include: Linear algebra, discrete mathematics, data structure, programming language and so on[4]. With the application of many subjects' knowledge, students generally reflect that the course of arithmetic analysis is "high, deep and difficult", which leads to students' low interest in learning and unsatisfactory learning effect.

\subsection{Weak foundation of students and lack of self-regulated learning ability}

Few students take the initiative to preview the content of the course, coupled with the limited class hours. For some classical algorithms, teachers can't give students a longer class time to think about the problem, seriously ignoring the lack of students' participation and interaction, resulting in the low quality of classroom teaching. If students can learn independently before class, understand the content of the teacher's lecture, think ahead of time about the problem, so that students can take the problem to listen to the lesson, the teaching effect will be better. 


\subsection{Lack of practical training in curriculum design}

At present our school Algorithm design and Analysis is a pure theory teaching course, the classroom mainly uses teaching, blackboard writing, slide show teaching methods, lack of actual combat experience. In this way, students can only passively accept the idea of the algorithm and forcibly memorize the steps of the algorithm, lacking the ability to solve practical problems independently and independently.

\subsection{Single examination mode}

In addition, the examination method of this course is closed-book test. Their examination questions are focused on the basic knowledge. Among them, the performance score accounts for $30 \%$, and the final examination paper score accounts for $70 \%$. This way of examination is easy to cause students to memorize book knowledge. Students' practical ability and innovation ability have not been significantly improved.

\section{The Teaching Method of "Project Oriented + Autonomous Learning + Practical Training"}

\subsection{Adopt Project-oriented Teaching Model to Increase Students' Interest in Learning}

Aiming at the problem of "difficult" in arithmetic analysis course and students' low interest in learning, teachers arouse students' interest in learning by using some project cases which are strong in application, subject close to life and students' interest. For different teaching knowledge points in each chapter of the Algorithm design and Analysis course, project cases can be constructed separately.

\subsection{Formulate "Autonomous Learning Task List" to Change Passive Learning into Active Participation}

The project case is made into a "task list of self-study", which is sent to the students in advance to help them clarify the content, objectives and methods of self-study before class. Under the guidance of "self-study task list", students use teaching materials and mobile terminals (computers, mobile phones, etc.) to carry out self-study after class. The content shown in the task list of self-regulated learning does not require the students to find the solution to the problem. The purpose is to arouse the students' strong interest in learning and let them come into the classroom with the problem in mind. Examples of projects and "self-learning task sheets" are as follows:

Table 1 Task list of Autonomous learning

\begin{tabular}{ll}
\hline \multicolumn{1}{c}{ Chapter } & \multicolumn{1}{c}{ Project title } \\
\hline \multirow{2}{*}{ Division strategy } & To help Professor Diogenes find a "good chip" \\
& A clever corporate salesman \\
Dynamic planning & $0-1$ knapsack problem \\
& Investment problem \\
Brute force method & What is the prim algorithm? \\
Greedy Algorithm & What is the kruskal algorithm? \\
& optimal path problem \\
\hline
\end{tabular}

The students are grouped freely, study independently in the extra-curricular time, get the study report and hand it in. The score of the report is a part of the assessment of the examination results, so as to encourage the students to study actively.

\subsection{Online Exercises in Competition to Improve Students' Practical Ability}

As to the problem that there is no practice teaching link in the course, the online question bank is used as the practice teaching platform to strengthen the ability of learning to apply. When assigning homework after class, students with strong ability are encouraged to complete the challenging questions in the online question bank, while students with general ability can choose to do simple questions.

\section{4 “N+1" Examination mode}

The course assessments are no longer measured by a single final exam paper. We combined the various aspects of assessment methods such as the scores of independent study report before class, class performance and attendance, and scores of online problem-solving practice questions after class. "1" represents the final exam paper score. This is conducive to the dynamic and comprehensive evaluation of 
the overall quality of students. In short, this test mode is simply referred to as the "N +1 " mode. The structure of the assessment method is shown in Fig. 1.
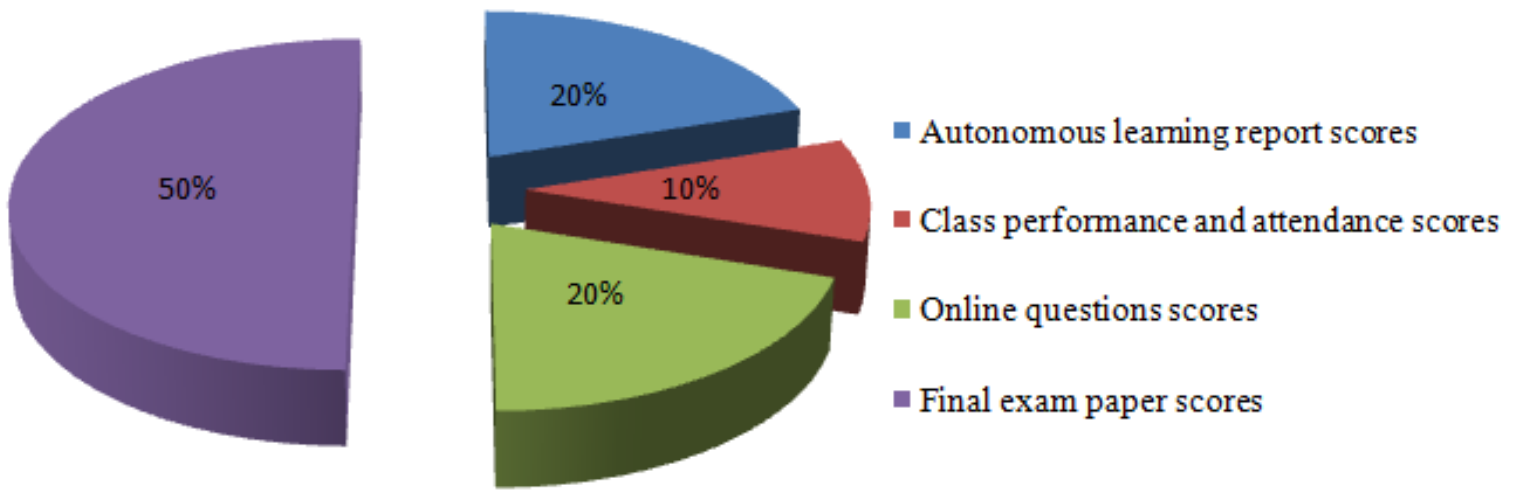

Fig.1 The structure chart of assessment

\section{Analysis of New Teaching Model}

By using the new teaching methods described in this paper, its advantages are mainly reflected in the following:

(1)Adopting the project-oriented teaching model can arouse students' interest in learning and subjective activity, which combines with the situation of students' source of applied technical undergraduate colleges and universities[5,6].

(2)Make "automatic learning task list" in order to cultivate students' self-learning ability. In the process of autonomous learning, through group cooperation, cultivate the spirit of teamwork of students, promote students to study together, make progress together, and create a good learning atmosphere.

(3)Thirdly, the online question bank is used as the practice teaching platform to cultivate the students' practical ability and improve the students' ability of programming.

(4) At last, the variety of assessment methods can focus on testing students' normal learning and process performance. Not only can it reduce the tremendous pressure that the final exam brings to the students, but it also avoids the centralized examination of “temporary cravings". This way can sti mulate students to learn and improve the quality of teaching.

\section{Experimental Results and Analysis}

In order to objectively evaluate the teaching reform scheme based on "project-oriented + Autonomous Learning + practical training" in algorithm design and analysis of classroom teaching effect, in this paper, two independent samples were examined in the experimental class and the compared class at three times. The experimental data were collected from Class 1-2 of Software engineering, Grade 2017, City College of Science and Technology Chongqing University. Class one is experimental class, class two is compared class. The compared class uses traditional teaching pattern, while the teaching in experimental class take place through "project-oriented + Autonomous Learning + practical training". The experimental results are shown in Table 2. 
Table 2 Statistical table of Unit test and final test

\begin{tabular}{cccc}
\hline Examination project & class & Number of people & Average score \\
\hline \multirow{2}{*}{ Test of third chapter } & Experimental class & 34 & 73.54 \\
& Compared class & 32 & 68.72 \\
Test of fourth chapter & Experimental class & 34 & 70.66 \\
& Compared class & 32 & 67.32 \\
\multirow{2}{*}{ Final test } & Experimental class & 34 & 78.26 \\
& Compared class & 32 & 72.13 \\
\hline
\end{tabular}

Through the implementation of the program, within the scope of the school to a greater extent to improve the status quo of teaching.

\section{Conclusions}

This paper analyzes and summarizes the existing problems of Algorithm design and Analysis in applied technology-oriented colleges and universities, discusses the teaching reform of this course, and puts forward a teaching reform scheme based on "Project Oriented + Autonomous Learning + Practice Training". Through the implementation of the program, within the scope of the school to a greater extent to improve the status quo of teaching, not only changed the way students learn passively, improve the quality of teaching, but also make the interaction between teachers and students more harmonious. It plays a major role in transforming the traditional education concept and fostering students' autonomous learning.

\section{Acknowledgment}

This paper is the research result of the 2018 Chongqing University of City College Science and Technology Transformation Pilot Project(City College Science and Technology, Chongqing University [2018] No. 93) and the Collaborative Education Project of the Ministry of Teaching(201702071100).

\section{References}

[1]. Sun Hongli, Ye Bin. On the Teaching Reform of Algorithm Design and Analysis Course [J]. Journal of Taiyuan Institute of Education, 2005 (4): 54-56

[2]. Qin Donghong, Chen Zhiyong. Teaching Research on Algorithm Design and Analysis Course[ J]. Computer Education, 2013(11): 98-101

[3]. Xiao Xiaoke, Chen Li. Discussion on Practical Teaching of Algorithm Design and Analysis[J]. Fujian Computer, 2009,5(10): 210

[4]. Sun Jun, Wu Xiaojun, Li Yueyang. Research on Teaching Methods of Computer Algorithm Design and Analysis [J]. Science and Technology Information, 2013(23): 173-174.

[5]. Xu nan. Research on Java Curriculum Teaching Reform on project-driven[J]. Education and Career, 2011,5 (14): 26-27

[6]. Li Yong. Teaching Research on "Algorithm Design and Analysis" Based on Practical Teaching[J]. Journal of Qujing Normal University, 2015,6(12):34-35 